\title{
Capacity Interaction in Brick Masonry under Simultaneous In-plane and Out-of-plane Loads
}

\author{
M. A. Najafgholipour ${ }^{1}$, M. R. Maheri $^{2 *}$ P. B. Lourenço ${ }^{3}$ \\ ${ }^{1} \mathrm{PhD}$ candidate, Department of Civil Engineering, Shiraz University, Shiraz, Iran, \\ ${ }^{2}$ Corresponding author, Professor of Civil Engineering, Shiraz University, Shiraz, Iran, \\ maheri@shirazu.ac.ir \\ ${ }^{3}$ Professor, ISISE, Department of Civil Engineering, University of Minho, Portugal
}

\begin{abstract}
A considerable number of numerical and experimental studies, carried out to-date to investigate the behaviour of masonry walls under seismic loading, have considered the inplane or the out-of-plane response of the wall separately without due consideration for any possible interaction between the two responses. In this paper, the results of a series of tests with different levels of simultaneous in-plane shear and out-of-plane bending actions on small brick walls are presented. The tests results indicate noticeable interaction between the in-plane shear and out-of-plane bending strengths of brick walls. Test results are also used to validate representing numerical models of wall panels. The combined in-plane/out-of-plane capacity interaction in full-scale walls having different aspect ratios is then investigated using these numerical models. It is found that the wall aspect ratio highly influences the interaction level, which must be considered in masonry design.
\end{abstract}

Keywords: masonry, brick wall, in-plane shear, out-of-plane bending, capacity interaction, seismic response

\section{INTRODUCTION}

A brick wall undergoing an earthquake global acceleration field is subjected to both in-plane and out-of-plane loads. The former results from the storey shear force under horizontal 
loading and the latter is either due to the out-of-plane inertia force caused by the considerable mass of the brick wall or the out-of-plane action of a flexible floor on the wall. The presence of one type of loading on a structural element affects the strength of that element against another type of loading. Considerable experimental, numerical and analytical studies have been carried out on the behaviour of masonry buildings, particularly under earthquake loading and mostly on the behaviour of brick walls.

As one of the earliest experimental works, Thompson and Johnson [1] investigated the tensile strength of brickwork as the main parameter for brick wall in-plane failure and it's relation to the angle between the load and the direction of the bed joints. Another early work was done by Sinha and Hendry [2], with a series of racking tests on brick walls with openings. They derived relations for the in-plane shear capacity of brick walls based on Mohr-Coulomb and maximum tensile strength criteria. More recently, Abrams [3] reported a series of pushover and cyclic tests on unreinforced brick walls and suggested relations for calculating the in-plane shear and bending strengths of these elements. Tomazevic [4] also investigated diagonal shear strength of brick walls and compared the results with those obtained through relations suggested by Euro-code 6 [5], showing some discrepancies in the results. The in-plane shear behaviour of confined brick walls has also been investigated experimentally by Tomazevic and Klemenk [6], Pourazin and Eshghi [7] and Riahi et al [8] and simple load displacement models are suggested for these elements. In some of the studies, the effects of the confining concrete ring beam on the strength and behaviour of brick wall was also investigated. Other investigators have concentrated on the brick-mortar bond strength and response under in-plane direct shear force, such as Atkinson et al [9], Elsakhawy et al [10], Abdou et al [11] and Maheri et al. $[12,13]$. The effect of mortar joints on the inplane shear strength of brick walls was also investigated by Maheri et al [14]; showing the considerable influence of the head joints on the response. 
Experimental and numerical investigations on masonry are often aimed at deriving simplified analytical models for the response or capacity. Although analytical methods have limitations, they are popular due to simplicity and relevance for design purposes. Most analytical methods have been presented for the in-plane shear response of masonry walls. Calderini et al [15] reported a series of existing analytical methods for calculating the inplane strength of unreinforced masonry walls. Bojsilivic et al [16] also reviewed the existing analytical methods for evaluating the in-plane strength of masonry walls and presented an approach for calculating the performance limits of masonry buildings. Roca [17] proposed simple equilibrium equations to calculate the ultimate strength of solid brick walls and walls with openings under concentrated or distributed gravity and lateral loads. Giordano et al [18] presented a simple formula for predicting the in-plane strength of masonry portals based on limit analysis approach. Benedetti and Steli [19] derived the lateral load-displacement curve for unreinforced and FRP reinforced masonry walls through analytical methods, assuming an elastic-perfectly plastic behaviour for the masonry material.

Considerable experimental work is also reported for the strength and response of brick walls under out-of-plane loads. Kanit and Atimatay [20] carried out a cyclic test on an unreinforced brick wall and presented its failure mode and hysteretic curve. Griffith et al [21] conducted a series of cyclic tests on full scale brick walls with different pre-compression levels and aspect ratios, with and without openings. Their results showed considerable post peak strength and displacement capacity in the walls resulting from the pre-compression. Derakhshan et al [22] carried out static one-way, out-of-plane bending tests on three brick walls with different height to thickness ratios and various pre-compression loads. They obtained a tri-linear force-displacement model for walls in one-way bending and concluded that pre-compression and slenderness are important parameters in the out-of-plane response. Meisl et al [23] carried out a series of out-of-plane shaking table tests on unreinforced brick 
walls subjected to three types of ground motions. The results showed that the type of ground motion did not have significant effects on the out-of-plane strength of walls. In a recent experimental study Maheri et al [14] highlighted the orthotropic nature of the out-of-plane response of brick walls. The failure mechanism of the orthotropic wall panels undergoing bidirectional bending initiated with a vertical crack as the stiffness of the wall in bending parallel to the bed joints far exceeds the stiffness of the wall in bending perpendicular to the bed joints. Following the softening of the wall parallel to the bed joint, caused by the vertical crack, the wall exhibited a relatively isotropic behaviour [14].

Several researchers performed out-of-plane tests on masonry prisms. Grimm and Tucker [24] derived a relation between the out-of-plane strength of brick walls and flexural strength of masonry prisms. Rao et al [25] and Pavia and Hanley [26], in similar experimental studies, investigated parameters such as mortar type and moisture content of masonry units affecting the flexural strength of prisms. They concluded that these parameters have significant effects on the flexural strength. Khalaf [27] proposed a new test set up with lower scatter in results for obtaining the flexural brick-mortar strength.

In addition to the above experimental works, numerous numerical investigations have also been carried out in recent years to further study the response of brick walls to in-plane and out-of-plane loading. A review of these studies is beyond the scope of this article and the reader is directed to [28-32] for a review.

Very few studies were carried out on the numerical response under simultaneous inplane and out-of-plane loading. Shapiro et al [33] studied the interaction of the in-plane and out-of-plane responses of brick infills in concrete frames. They carried out a series of tests to investigate the effects of in-plane cracks on the out-of-plane strength. Their test results showed that the in-plane cracks may reduce the out-of-plane strength of infills up to $100 \%$. A similar experimental study was carried out by Falangan et al [34] on brick infills in steel 
frames. Recently, Hashemi and Mosalam [35] conducted an in-plane shake table test on a concrete infilled frame, subsequently used to calibrate a numerical model that was further developed to include out-of-plane loading. Also, Milani carried out a 3D heterogeneous upper bound limit analysis of multi-leaf brick masonry walls subjected to simultaneous in-plane and out-of plane loading [36]. In that study, under the assumption of associated plasticity for the constituent materials, mortar joints were reduced to interfaces with a Mohr-Coulomb failure criterion with tension cut-off and cap in compression, whereas for bricks a Mohr-Coulomb failure criterion was adopted.

The absence of experimental investigations directly addressing the in-plane shear/ out-of-plane bending capacity interaction in brick masonry in the literature is the main reason for the present study, which complements the experimental campaign with the numerical simulation of the results and a parametric study on the influence of the aspect ratio of the panels.

\section{EXPERIMENTAL PROGRAM}

A series of tests are conducted here on wallets to study the in-plane and out-of-plane capacity interaction and to determine the interaction curve for brick walls. Next, a discussion on the adopted test specimens, set up, procedure and results is given.

\subsection{Test Specimens}

In total, twenty seven, single-layer square brick wall panels were constructed for the experiments. All panels were of the same size and materials using constant workmanship and post-construction treatment, aiming at obtaining a moderate scatter in the results. The wall panels were $60 \mathrm{~cm}$ by $60 \mathrm{~cm}$ and $10 \mathrm{~cm}$ thick. To ensure that the pure in-plane shear failure of 
the wall panels develops indeed in the form of a diagonal line crack running through both the mortar and brick units, it was decided to use stronger mortar and slightly weaker brick units. Therefore, in constructing the panels, compressed vertically perforated calcium-silicate brick units were used with dimensions $22 \mathrm{~cm}$ (length), $10 \mathrm{~cm}$ (width) and $5.0 \mathrm{~cm}$ (height). These are the best type of engineered bricks available locally with low variation in quality and strength. The mortar was made of ordinary Portland cement and very fine aggregate (passing sieve \# 20) with a weight ratio of 1:3, providing a high strength mortar. The wall panels were also cured under polythene sheet for 28 days against loss of moisture and for uniformity of treatment. Such treatment was shown previously by Maheri et al $[13,14]$ to result in increased brick-mortar bond strength and low variation in the results. A number of samples were also made for the material and prism tests, including: compressive and tensile tests on mortar; compressive and flexural tests on brick units; shear, compression and bending capacity tests of brickwork; and determination of modulus of elasticity of mortar, brick units and brickwork. The obtained properties are listed in Table 1 and Table 2, together with the standards followed and the numbers of specimens used for each test.

\subsection{Test Set-up}

Based on the observations made on the behaviour of walls during earthquakes and supported by experimental research reported in the literature, a most relevant in-plane shear failure mode in unreinforced brick walls is diagonal shear cracking. This failure mode is characterized by a diagonal crack perpendicular to the maximum tensile stress in the wall panel. There are a number of in-plane shear test set-ups (also known as diagonal tension or compression tests), see Vilet [37] and the ASTM-E519-10 [38] was utilised here, regarding the size and preparation of the specimens, as well as the test set-up and procedure. In this test, the brick wall panel is subjected to a static diagonal compressive force until failure. A 
number of researchers, including Calderini et al [39], Gabor et al [40], Brignolia et al [41] and Borri et al [42], have recently used this particular test to determine the in-plane shear strength of brick walls.

For the present study, a minor modification was needed in the test set-up so that simultaneous application of in-plane and out-of-plane loads to the wall panels could be carried out. For this purpose, a reaction frame was designed and constructed in such a way that it did not confine the brick panel and also did not reduce the effective dimensions of the panel. A square steel frame having internal dimensions slightly smaller than the brick panel was positioned vertically on one face of the panel. To avoid local stress concentration at the interface between the rough surface of brickwork and the smooth surface of the steel frame, a thin layer of fast setting gypsum was applied at the interface.

The loading frame used for the tests was manufactured to accommodate the test procedure, see Fig. 1. The earthquake-induced out-of-plane loading on a wall is primarily due to the out-of-plane inertia of the wall. Although the mass of the wall is generally uniformly distributed, the same cannot be said about the acceleration. Following a bowl-shaped vibration mode, the central parts of the wall undergo larger accelerations compared to its boundaries. Therefore, the actual load distribution of load is not uniform and follows a more complex pattern. Due to experimental limitations in applying a complex non-uniformly distributed load, the most representative and easier to apply out-of-plane load for the experiments was considered to be a horizontally-applied central point load. The in-plane load was applied vertically on the diagonal. The in-plane diagonal compressive load and out-ofplane point load were applied to the panels using $300 \mathrm{kN}$ capacity hydraulic jacks.

Due to the relatively low out-of-plane strength of the brick panels, the out-of-plane load was exerted to the panel through a load ring at smaller load steps of $250 \mathrm{~N}$. In each load step, the panel displacements were measured with displacement transducers and recorded 
with a digital data logger. The test set-up with the locations of load application and measuring sensors is shown in Fig. 2. One hydraulic jack positioned vertically on one diagonal applied the in-plane load (P-I) and another jack placed horizontally at the centre of the panel applied the out-of-plane load (P-O). Three LVDTs were used to measure the displacements of the panels during loading: two transducers (S1 and S2), positioned on the horizontal diagonal, measured in-plane displacements on this diagonal and one transducer (S3), positioned at the centre of the panel directly opposite to the central loading jack (P-O), measured the maximum out-of-plane displacement of the panel.

\subsection{Test Program and Results}

The experimental program on the wall panels was conducted in three phases. First, the ultimate pure in-plane shear capacities of the wall panels were determined. For this purpose and to verify the repeatability of the tests, three panels were subjected to in-plane load (P-I) only. The mode of failure of all three panels was characterised by a sudden diagonal crack (Fig. 3) and the coefficient of variation in the ultimate strengths was very small (3\%); indicating the uniformity of panel construction and performance. The average ultimate inplane diagonal strength of the panels was $48 \mathrm{kN}$.

In the second phase, the behaviour and capacity of the wall panels under out-of-plane bending alone was investigated. For this purpose, three out-of-plane loading conditions were considered; (i) two-way bending, (ii) bending parallel to the bed joints and (iii) bending perpendicular to the bed joints. The objective of the two latter tests was to obtain the orthotropic tensile strengths of brickwork in perpendicular directions. In total, nine wall panels were tested in this phase; three for each condition. Similarly to the in-plane tests, the results of the tests regarding the mode of failure and the ultimate flexural capacity were very similar. Fig. 4 shows the typical mode of failure of the brick panels under two-way bending 
tests. The failure of the panels occurred in the form of two cross-inclined cracks at an ultimate point load equal to $11.8 \mathrm{kN}(3.7 \%)$. The failure of the panels in bending parallel to the bed joints was a single line crack along a bed joint, while the failure of panels in bending perpendicular to bed joints was a single line crack through bricks and head joints. The ultimate loads applied were $3.37 \mathrm{kN}(6.2 \%)$ and $18 \mathrm{kN}(5.6 \%)$, respectively. The values inside brackets provide the coefficient of variation. Average load-displacement curves for the test panels under the three different bending conditions are presented in Fig. 5.

After the preliminary tests, the next phase of the experimental program consisted of a series of tests on panels with different combinations of in-plane and out-of-plane loads. In each test, the wall panel was first subjected to a certain value of out-of-plane load. Then, while the out-of-plane load was kept constant, the in-plane diagonal compressive load was monotonically increased until failure. Each load combination was carried out on three panels for repeatability and the results were averaged. The differences between the results obtained for the three panels in each load combination were again small (average coefficient of variation of 5.0\%); indicating the consistency of the results. In total, five load combinations were tested, corresponding to out-of-plane loads of $33 \%, 50 \%, 67 \%, 83 \%$ and $90 \%$ of the ultimate flexural strength of the panels.

The load-displacement curves for the test panels are presented in Fig. 6. As expected, the in-plane shear capacity of the panel reduces with an out-of-plane load increase. The shear stiffness of the brick panels is also reduced with increasing out-of-plane load.

The failure mechanism of the wall panels under combined in-plane and out-of-plane loads is a combination of the in-plane diagonal shear and the out-of-plane bending failures discussed previously. The crack pattern of the panels subjected to low levels of out-of-plane loads follows a diagonal shape. With increasing out-of-plane load, bending cracks accompany the diagonal shear cracks at failure. 
The reduction in the in-plane shear strength of brick wall panels with the out-of-plane load is more profound when the out-of-plane load is closer to the out-of-plane capacity of the panel. Similarly, the out-of-plane bending capacity is reduced in the presence of the in-plane shear loads. To gain a better insight into the in-plane shear and out-of-plane bending capacity interaction, the test results are plotted, in normalised form, in Fig. 7. A strong interaction between the in-plane and out-of-plane capacities of the tested panels is found which follows closely a circumference.

\section{NUMERICAL STUDIES}

In this section, the results of a numerical study aimed at evaluating the in-plane and out-ofplane interaction curves for full scale brick walls are presented. For this propose, results obtained from the experiments discussed in the previous section are first utilised to validate the numerical models adopted. The interaction curves are then evaluated numerically for full scale brick walls having three different aspect ratios (Height/Length) of 0.5, 1 and 2 .

Due to the complex in-plane and out-of-plane loading, for numerical modelling of the test panels, suitable continuum macro model based on anisotropic plasticity is adopted [30] for the three dimensional analysis of brick walls. This material model is implemented in software Diana V9.4 [43] via a user supplied subroutine.

\subsection{Anisotropic Continuum Model}

The adopted composite yield criterion in this model, [30] is based on the plane stress anisotropic yield criterion of Lourenço [28], in the typical five stress component space, with two normal stresses $\sigma_{\mathrm{x}}$ and $\sigma_{\mathrm{y}}$ and three shear stresses $\tau_{\mathrm{xy}}, \tau_{\mathrm{yz}}$ and $\tau_{\mathrm{xz}}$. The composite yield criterion includes a Hill type criterion for compression and a Rankine type criterion for 
tension (Fig. 8). The Rankine type yield surface, for an orthotropic material with different tensile strengths along the $x$ and $y$ directions, is given by:

$$
f_{1}=\frac{\left(\sigma_{x}-\overline{\sigma_{t x}}\left(\kappa_{t}\right)\right)+\left(\sigma_{y}-\overline{\sigma_{t y}}\left(\kappa_{t}\right)\right)}{2}+\sqrt{\frac{\left(\sigma_{x}-\overline{\sigma_{t x}}\left(\kappa_{t}\right)\right)-\left(\sigma_{y}-\overline{\sigma_{t y}}\left(\kappa_{t}\right)\right)}{2}+\alpha \tau_{x y}^{2}}
$$

In the above equation, $\overline{\sigma_{t x}}$ and $\overline{\sigma_{t y}}$ are the yield values along $\mathrm{x}$ (parallel to bed joints) and $\mathrm{y}$ (normal to bed joints) directions. The scalar $\kappa_{t}$ measures the amount of softening simultaneously in the two material axes. The parameter $\alpha$ which controls the shear stress contribution to failure reads:

$$
\alpha=\frac{f_{t x} f_{t y}}{\tau_{u, t}^{2}}
$$

where, $f_{t x}, f_{t y}$ and $\tau_{u t}$ are respectively, the uniaxial tensile strengths in the $x$ and $y$ directions and the pure shear strength.

The simplest compressive yield criterion features different compressive strengths along the two material axes and is a rotated centered ellipsoid in the full stress space (Hill type criterion). The expression for such a quadric can be written as:

$$
f_{2}=\frac{\overline{\sigma_{c y}}\left(\kappa_{c}\right)}{\overline{\sigma_{c x}}\left(\kappa_{c}\right)} \sigma_{x}^{2}+\beta \sigma_{x} \sigma_{y}+\frac{\overline{\sigma_{c x}}\left(\kappa_{c}\right)}{\overline{\sigma_{c y}}\left(\kappa_{c}\right)} \sigma_{y}^{2}+\gamma\left(\tau_{x y}^{2}+\tau_{y z}^{2}+\tau_{x z}^{2}\right)-\overline{\sigma_{c x}}\left(\kappa_{c}\right) \overline{\sigma_{c y}}\left(\kappa_{c}\right)=0
$$

where, $\overline{\sigma_{c x}}\left(\kappa_{c}\right)$ and $\overline{\sigma_{c y}}\left(\kappa_{c}\right)$ are, respectively, the yield values along the material $x$ and $y$ axes.

The $\beta$ and $\gamma$ values are additional material parameters that determine the shape of the yield criterion. They control, respectively, the coupling between the normal stress values 
and the shear stress contribution to failure. The parameter $\gamma$ can be obtained from the following equation:

$$
\gamma=\frac{f_{c x} f_{c y}}{\tau_{u, c}^{2}}
$$

In equation (4), $f_{c x}, f_{c y}$, and $\tau_{u c}$ are respectively, the uniaxial compressive strengths in the $x$ and $y$ directions and the pure shear strength.

In total, nine elastic and twelve inelastic parameters are needed in Diana software to compose the proposed anisotropic material model. The elastic parameters are the Young's modulus, E, the Poisson's ratio, $v$ and the shear modulus, G, of the anisotropic material. The inelastic parameters for tension regime are the tensile strength along $x$ and $y$ directions $\left(f_{t x}\right.$ and $\left.f_{t y}\right)$, the fracture energies in tension along $x$ and $y$ directions $\left(G_{f x}\right.$ and $\left.G_{f y}\right)$ and parameter $\alpha$. The inelastic parameters in compression are the compressive strength along $x$ and $y$ directions $\left(f_{c x}\right.$ and $\left.f_{c y}\right)$, the fracture energies in compression along $x$ and $y$ directions $\left(G_{f c x}\right.$ and $\left.G_{f c y}\right)$, the parameters $\beta$ and $\gamma$, and the parameter $k_{c}$ that represents the equivalent plastic strain at peak compressive strength.

\subsection{Verification of the Numerical Model}

The Diana software's layered shell element (CQ40L) with seven Simpson integration points along the height is used for modelling the test panels subjected to combined loading. The material parameters used in the models are derived from the materials tests conducted in Section 2, from literature (see [44] for details on recommended inelastic properties) and from the pure shear and bending tests. The compressive strengths and the modulus of elasticity of masonry in two orthogonal directions (along and normal to bed joints), are obtained from the compressive tests on masonry prisms discussed in section 2.1 (see Table 2). The material parameters used for these studies are listed in Tables 3 to 5. The fracture energy values used 
in this study (listed in Tables 4 and 5) are obtained from the ductility factor, equal to the ratio between the fracture energy and the ultimate strength, for the horizontal tensile strength and the compressive strength. For the vertical tensile strength, the fracture energy values are obtained from the few tests available in the literature [45]. For the compressive strength, a ductility factor of $1.25 \mathrm{~mm}$ is used [44]. The tensile strength parallel to the bed joints is controlled by the failure of the brick and a ductility factor of $0.05 \mathrm{~mm}$ was used [44]. Also, it is noted that the flexural tensile strength cannot be directly compared to the uniaxial tensile strength, because the flexural tensile strength depends on the height of the specimen and on the fracture energy. As a result, masonry direct tensile strength in each direction is considered to be $50 \%$ of the indirect tensile strength in that direction listed in Table 2 .

Similar to tests discussed in Section 2, the panel was subjected to three different types of loading. These included pure in-plane diagonal compressive force, pure out-of-plane point load and simultaneous in-plane and out-of-plane loading. The load-displacement curve obtained from the numerical analysis of the brick panel under in-plane loading is compared with that obtained from the experiments in Fig. 9. Similar comparisons are made for the numerical and experimental results of the panel under out-of-plane loading in Fig. 10. Comparisons of the load-displacement curves obtained from the tests and the numerical studies show good agreements between the results in both cases.

The normalised numerical interaction curve for the panel undergoing different levels of simultaneous in-plane and out-of-plane loading is compared with the interaction curve obtained from the experiments in Fig. 11. This figure also shows that the numerical model used can predict well the in-plane shear, out-of-plane bending capacity interaction in brick masonry walls. The difference between experimental and numerical results is below $10 \%$ and the numerical results in the central part of the interaction curve are conservative. 
Regarding the modes of failure of the panels, it was noted that, in the numerical panels subjected to the in-plane, out of plane and combined loading the modes of failure were more or less similar to the failure patterns of their corresponding test panels. The in-plane failure occurs with a line crack along the compression diagonal and the out of plane failure occurs with a crossed crack in the tension face of the wall. It is interesting to note that, similarly to the test failure described in section 2.3 , the failure of the panels under combined loading with low values of out-of-plane loads, occurs as a diagonal crack. Conversely, in the numerical panels undergoing considerable values of out-of-plane load, the failure occurs in the form of the panel becoming unstable due to large out-of-plane displacement at its centre.

It was stated above that the experimental interaction curve appears to follow a circular line. In Fig. 11 a quarter circle with a radius equal to unity is drawn for comparison with the experimental and the numerical interaction curves. Both interaction curves closely follow the circular curve. The experimental curve matches well the circular curve at the end regions, where the in-plane shear force or the out-of-plane bending load is dominant. In the central part of the interaction curve, the match is less profound, being the numerical and experimental curves external and internal to the circle line. As mentioned earlier, in the experimental program, due care was given to minimize the effects of boundary conditions. However, these effects, together with the possible effects of scale factor due to the size of the specimens tested, may account for the small deviation of the experimental interaction curve from the circle line in the central sections.

\subsection{Interaction in Full Scale Walls}

After verifying the numerical model on the small brick panel, numerical investigation of the in-plane and the out-of-plane capacity in full size brick walls are carried out. Three different walls with dimensions of $3 \mathrm{~m} \times 6 \mathrm{~m}, 3 \mathrm{~m} \times 3 \mathrm{~m}$ and $6 \mathrm{~m} \times 3 \mathrm{~m}$, respectively, corresponding to aspect 
(height/length) ratios of $0.5,1$ and 2, are investigated. Similar to the brick panels, the fullscale walls were one brick thick. Displacement-controlled nonlinear analyses of the walls under pure in-plane and out-of-plane loads were first carried out and their respective capacities were determined. The out-of-plane load was now applied in a uniformly distributed way on the entire area of the wall, to better represent the seismic action. The in-plane load was applied horizontally at the top of the wall. The top and bottom edges of the walls were restrained with compression only supports in vertical direction under the in-plane loading. This allowed the wall to separate from its support if the edge was in tension. The bottom edge of the wall was also restrained from moving in the horizontal direction.

After the pure in-plane and out-of-plane capacities of the walls were established, the walls were subjected to simultaneous loading and their interactive capacities were determined. Loading of the walls was carried out in the same manner as that carried out for the brick panel; i.e. a specific amount of constant out-of-plane load was first applied to the wall, followed by the incremental application of the in-plane load until the wall failed. The shear stress distribution in the brickwork of the square wall at the middle plane, corresponding to an out-of-plane load/capacity ratio of 0.4 at $50 \%$ of the ultimate capacity and prior to failure are shown in Fig. 12.

The normalized interaction curves obtained for the walls with the three different ratios are plotted in Fig. 13. A strong capacity interaction can be observed whereby the presence of the out-of-plane load causes reduction in the in-plane capacity of the wall and vice-versa. The interaction is particularly strong at higher loads and the shapes of the interaction curves in the three walls are different, indicating the influence of the wall's aspect ratio on the interaction. The effect of out-of-plane load on the in-plane shear capacity is the lowest for the wall with $\mathrm{H} / \mathrm{L}=0.5$ and is the highest for the wall with $\mathrm{H} / \mathrm{L}=2.0$. This can be attributed to the fact that 
the critical bending (bending perpendicular to the bed joints) is less relevant in slender (tall) walls.

Further work is necessary to derive at definitive in-plane, out-of-plane capacity interaction relations in brick walls. As a preliminary result, the minimum envelop of the three curves can tentatively and conservatively be used, given by the equation:

$\left(\frac{P_{i l}}{P_{i c}}\right)^{1.8}+\left(\frac{P_{o l}}{P_{o c}}\right)^{1.05}=1$

where, $P_{i l}$ and $P_{o l}$ are respectively the in-plane and the out-of-plane loads and $P_{i c}$ and $P_{o c}$ are respectively the pure in-plane and the pure out-of-plane capacities.

\section{CONCLUSIONS}

The results of the investigations presented in this paper can be summarised as follows;

1. Noticeable interaction exists between the in-plane shear and out-of-plane bending capacities of brick walls. The interaction is particularly strong when one of the load types is near the wall's corresponding ultimate capacity in any of the loading directions. It is therefore recommended that this capacity interaction is taken into consideration when designing, assessing vulnerability or retrofitting masonry buildings.

2. An anisotropic continuum model presented for three dimensional modelling and analysis of brick walls and masonry shells is found to accurately predict the in-plane, out-of-plane capacity interaction in unreinforced brick walls.

3. The in-plane shear/out-of-plane bending capacity interaction curve is a function of the aspect ratio of the wall, deviating from the circumference form. A lower bound elliptical equation has been proposed. 


\section{REFERENCES}

[1] Johnson, F. B., Thompson, J. N., Development of diametral testing procedures to provide a measure of strength characteristics of masonry assemblages, in Designing, engineering and constructing with masonry products, Gulf Publishing Company, Houston, 1969: 51-57.

[2] Sinha, B. P., Hendry, A. W., Racking tests on storey-height shear wall structures with openings subjected to pre-compression. Designing, engineering and constructing with masonry products, Gulf Publishing Company, Houston, 1969: 192-199.

[3] Abrams, D. P., Strength and behavior of unreinforced masonry elements, Proceedings of the $10^{\text {th }}$ world conference on earthquake engineering, Madrid, 1992: 3475-3480.

[4] Tomazevic, M., Shear resistance of masonry walls and Eurocode 6: shear versus tensile strength of masonry, Materials and Structures, 2009; 42: 889-907.

[5] CEN (2005) Eurocode 6: Design of Masonry Structures, part 1-1: Common rules for reinforced and unreinforced masonry structures. EN 1996-1-1:2005, Brussels.

[6] Tomasevic, M., Klemenc, I., Seismic behaviour of confined masonry walls, Earthquake Engineering and Structural Dynamics, 1997; 26: 1059-1071.

[7] Pourazin, Kh., Eshghi, S., Experimental and analytical studies for development of capacity curves in a confined masonry wall, Journal of Performance for Constructed Facilities, 2009; 5: 123-134.

[8] Riahi, Z., Elwood, K. J., Alcocer, S. M., Backbone Model for Confined Masonry Walls for Performance-Based Seismic Design, J. Structural Engineering, ASCE, 2009; 135(6): 644654.

[9] Atkinson, R. H., Amadei, B. P., Saeb, S., Sture, S., Response of masonry bed joints in direct shear, J. Structural Engineering, ASCE, 1989; 115(9): 2276-2296.

[10] El-Sakhawy, N. R., Raof, H. A., Gouhar, A., Shearing behaviour of joints in load bearing masonry wall, J. Materials in Civil Engineering, 2002;14(2): 145-150.

[11] Abdou, L., Saada, R. A., Meftah, F., Mebarki, A., Experimental investigation of the brick-mortar interface behavior, Experimental investigation of the mortar joint in masonry structures, Mechanics Research Communications, MRC 969, 2005.

[12] Maheri, M. R., Sherafati M. A., The effects of humidity and other environmental parameters on the shear strength of brick walls; evaluation of field test data, Materials and Structures. 2012, DOI: 10.1617/s11527-011-9809-7.

[13] Maheri, M. R., Motielahi, F., Najafgholipour, M. A., The effects of pre and post construction moisture condition on the in-plane and out-of-plane strengths of brick walls, Materials and Structures, 2011; 44(2): 541-559.

[14] Maheri, M. R., Najafgholipour, M. A., Rajabi, A. R., The influence of mortar head joints on the in-plane and out of plane seismic strength of brick masonry walls, Iranian J. Science and Technology, 2011; 35: 63-79. 
[15] Calderini, C., Cattari, S., Lagomarsino, S., In-plane strength of unreinforced masonry piers, Earthquake Engineering and Structural Dynamics, 2010; 38: 243-267.

[16] Bosiljkov, V., Page, A. W., Bosiljkov, V. B., Zarnic, R., Evaluation of the seismic performance of brick masonry walls, Structural Control and Health Monitoring, 2008; 32: 124-135.

[17] Roca, P., Assessment of masonry shear-walls by simple equilibrium models, Construction and Building Materials, 2006; 20: 229-238.

[18] Giordano, A., De Luca, A., Mele, E., Romano, A., A simple formula for predicting the horizontal capacity of masonry portal frames, Engineering structures, 2007; 29: 2109-2123.

[19] Benedetti, A., Steli, E., Analytical models for shear-displacement curves of unreinforced and FRP reinforced masonry panels, Construction and Building Materials, 2008; 22: 175-185.

[20] Kanit, R. and Atimtay, E., Experimental Assessment of the Seismic Behavior of LoadBearing Masonry Walls Loaded Out-of-Plane, Turkish Journal of Engineering and Environment Science, 2006; 22: 101-113.

[21] Griffith, M. C., Vaculik, J., Lam, N. T. K., Wilson, J., Lumantarna, E. (2007), Cyclic testing of unreinforced masonry walls in two-way bending, Earthquake Engineering and Structural Dynamics, 36, 801-821.

[22] Derakhshan, H., Ingham, J. M., Griffith, M. C., Tri-linear force-displacement models representative of out-of-plane unreinforced masonry wall behaviour, Proceedings of the $11^{\text {th }}$ Canadian masonry symposium, Toronto, 2009.

[23] Meisle, C. S., Elwood, K. J., Ventura, C. E., Shake table tests on the out-of-plane response of unreinforced masonry walls, Canadian Journal of Civil Engineering, 2007; 34 : 1381-1392.

[24] Grimm, C. T. and Tucker, R. L., Flexural strength of masonry prisms versus wall panels, J. Structural Engineering, ASCE, 1985; 111(9): 2021-2032.

[25] Rao, K. V. M., Reddy, B. V. V., Jagadish, K. S., Flexural bond strength of masonry using various blocks and mortars, Materials and Structures, 1996; 29: 119-124.

[26] Pavia, S., Hanley, R., Flexural bond strength of natural hydraulic lime mortar and clay brick, Materials and Structures, 2009; 40: 230-245.

[27] Khalaf, M., New Test for Determination of Masonry Tensile Bond Strength, J. Materials in Civil Engineering, ASCE, 2005; 17(6): 725-732.

[28] Lourenco, P. B., Borst, R. D. and Rots, J. G. (1997), “A plane stress softening plasticity model for orthotropic materials." International Journal for Numerical Methods in Engineering, 1997; 40: 4033-4057.

[29] Lemos, J. V., Discrete element modeling of masonry structures. International Journal of Architectural Heritage, 2007; 1: 190-213.

[30] Lourenço, P. B., Anisotropic softening model for masonry plates and shells, Journal of Structural Engineering, ASCE, 2000; 126(9): 1008-1016. 
[31] Lourenço, P. B., Milani, G., Tralli, A., Zucchini, A., Analysis of masonry structures: review of and recent trends of homogenisation techniques, Canadian Journal of Civil Engineering, 2007; 34 (11):1443-1457.

[32] Mistler, M., Anthoine, A., Butenweg, C., In-plane and out of plane homogenization of masonry, Computers and Structures, 2007; 85: 1321-1330.

[33] Shaprio, D., Uzarski, J., Webster, M., Angel, R., Abrams, D., Estimating out of plane strength of cracked masonry infills, University of Illinois at Urbana-Champaign, Civil Engineering Studies, Structural Research Series No. 588, 1994.

[34] Flanagan, R. D., Bennett, R. M., Bidirectional behaviour of structural clay tile infilled frames, J. Structural Engineering, ASCE, 1999; 125(3): 236-244.

[35] Hashemi, A., Mosalam, K. M., Seismic Evaluation of Reinforced Concrete Buildings Including Effects of Masonry Infill Walls, Pacific Earthquake Engineering Research Center, University of California, Berkeley, PEER Report 2007/100.

[36] Milani G. , 3D upper bound limit analysis of multi-leaf masonry walls, International Journal of Mechanical Sciences, 2008:50(4); 817-836.

[37] Vilet, M. R. A. V., Shear test on masonry panels: Literature survey and proposal for experiments, TNO Building and construction research, 2004-CI-R0171.

[38] American Society for Testing and Materials (ASTM), ASTM E 519-02, standard test method for diagonal tension (shear) in masonry assemblages, 2002.

[39] Calderini, C., Cattari, S., Lagomarsino, S., The use of the diagonal compression test to identify the shear mechanical parameters of masonry, Construction and Building Materials, 2010; 46: 677-655.

[40] Gabor, A., Ferrier, E., Jacquelin, E., Hamelin, P., Analysis and modelling of the in-plane shear behavior of hollow brick masonry panels, Construction and Building Materials, 2006; 20: $308-321$.

[41] Brignola, A., Frumento, S., Lagomarsino, S., Podesta', S., Identification of shear parameters of masonry panels through the in situ diagonal compression test, Int. J. Architectural Heritage, 2009; 3: 52-73.

[42] Borri, A., Castori, G., Corradi, M., Speranzini, E., Shear behaviour of unreinforced and reinforced masonry panels subjected to in situ diagonal compression tests, Construction and Building Materials, 2011; 20: 308-321.

[43] Diana-Finite Element Analysis, User's Manual, Published by TNO Diana BV. Schoemakerstraat 97, 2628 VK Delft, The Netherlands.

[44] Lourenço, P. B., Recent advances in masonry structures: Micromodelling and homogenisation, em: Multiscale Modeling in Solid Mechanics: Computational Approaches, Eds. U. Galvanetto, M.H. Ferri Aliabadi, Imperial College Press, p. 251-294 (2009).

[45] van der Pluijm, R., Out of plane bending of masonry: Behaviour and strength.

Ph.D. Dissertation, Eindhoven University of Technology, The Netherlands (1999). 


\section{List of Tables}

Table 1. Material properties of the brick and mortar Table 2. Material Properties of the masonry prism Table 3. Elastic parameters

Table 4. Inelastic parameters in tension regime

Table 5. Inelastic parameters in compression regime

\section{List of Figures}

Fig. 1. Test set-up for simultaneous application of in-plane and out-of-plane loads

Fig. 2. Position of loading jacks (P) and LVDT sensors (S)

Fig. 3. Failure of the wall panels under in-plane shear load

Fig. 4. Typical out-of-plane tests of wall panels; (a) one way bending parallel to bed joints and (b) two-way bending

Fig.5. Average out-of-plane load-displacement curves; (a) two way bending, (b) one way bending

Fig. 6. Average in-plane load-displacement curves for different in-plane, out-of-plane load combinations

Fig.7. In-plane/out-of-plane capacity interaction curve for the wall panel

Fig. 8. The adopted plane stress anisotropic yield criterion [28]

Fig. 9. The load-displacement curves for panel under in-plane loading

Fig. 10. The load-displacement curves for panel under out-of-plane loading

Fig. 11. Normalized in-plane/out-of-plane capacity interaction curves for the brick panel

Fig. 12. Shear stress distribution in the brickwork of the square wall at the tension plane, corresponding to an out-of-plane load/capacity ratio of 0.4 at (a) $50 \%$ of the ultimate capacity and (b) at failure

Fig. 13. Normalized in-plane/out-of-plane capacity interaction curves for the full-scale walls 
Table 1. Material properties of the brick and mortar (The values inside brackets indicate the coefficient of variation)

\begin{tabular}{|c|c|c|c|c|c|c|}
\hline \multirow{2}{*}{ Property } & \multicolumn{3}{|c|}{ Brick } & \multicolumn{3}{|c|}{$\begin{array}{c}\text { Mortar } \\
\text { (cement-sand) }\end{array}$} \\
\hline & Value & Standard & $\begin{array}{c}\text { No. of } \\
\text { Specimens }\end{array}$ & Value & Standard & $\begin{array}{c}\text { No. of } \\
\text { Specimens }\end{array}$ \\
\hline $\begin{array}{l}\text { Comp. } \\
\text { strength } \\
\text { (MPa) }\end{array}$ & 11 & $\begin{array}{c}\text { ASTM C67- } \\
11\end{array}$ & 5 & 34 & $\begin{array}{c}\text { ASTM } \\
\text { C579-01 }\end{array}$ & 6 \\
\hline $\begin{array}{l}\text { Flexural } \\
\text { tensile } \\
\text { strength } \\
(\mathrm{MPa})\end{array}$ & 2.0 & $\begin{array}{c}\text { ASTM C67- } \\
11\end{array}$ & 5 & - & - & - \\
\hline $\begin{array}{c}\text { Direct } \\
\text { tensile } \\
\text { strength } \\
(\mathrm{MPa})\end{array}$ & - & - & - & 4.4 & $\begin{array}{l}\text { ASTM- } \\
\text { C307-03 }\end{array}$ & 6 \\
\hline $\begin{array}{l}\text { Young's } \\
\text { modulus } \\
(\mathrm{MPa})\end{array}$ & 7500 & - & 4 & 12000 & $\begin{array}{c}\text { ASTM E111 } \\
-04\end{array}$ & 3 \\
\hline $\begin{array}{l}\text { Shear bond } \\
\text { Strength } \\
\text { (MPa) }\end{array}$ & - & - & - & 5.24 & - & 6 \\
\hline $\begin{array}{c}\text { Water } \\
\text { absorption } \\
\text { rate (\%) }\end{array}$ & 17.5 & $\begin{array}{c}\text { ASTM C67- } \\
11\end{array}$ & 5 & - & - & - \\
\hline
\end{tabular}

Table 2. Material Properties of the masonry prism

\begin{tabular}{|c|c|c|c|}
\hline Property & Value & Standard & $\begin{array}{c}\text { No. of } \\
\text { Specimens }\end{array}$ \\
\hline Compressive strength normal to bedjoints (MPa) & 8 & $\begin{array}{c}\text { ASTM C1314- } \\
11 \mathrm{a}\end{array}$ & 5 \\
\hline Compressive strength parallel to bedjoints (MPa) & 4 & - & 5 \\
\hline Flexural tensile strength normal to bedjoints (MPa) & 0.5 & ASTM E518-10 & 5 \\
\hline Flexural tensile strength parallel to bedjoints (MPa) & 5.0 & - & 3 \\
\hline Young's modulus normal to bedjoints (MPa) & 8000 & $\begin{array}{c}\text { ASTM C1314- } \\
11 \mathrm{a}\end{array}$ & 5 \\
\hline Young's modulus parallel to bedjoints (MPa) & 12000 & - & 5 \\
\hline
\end{tabular}


Table 3. Elastic parameters

\begin{tabular}{|c|c|c|c|c|c|c|c|c|}
\hline \multicolumn{3}{|c|}{ Young's modulus (MPa) } & \multicolumn{3}{c|}{ Poisson's ratio } & \multicolumn{3}{c|}{ Shear modulus (MPa) } \\
\hline $\mathrm{E}_{\mathrm{x}}$ & $\mathrm{E}_{\mathrm{y}}$ & $\mathrm{E}_{\mathrm{z}}$ & $\vartheta_{x y}$ & $\vartheta_{x z}$ & $\vartheta_{y z}$ & $\mathrm{G}_{\mathrm{xy}}$ & $\mathrm{G}_{\mathrm{xz}}$ & $\mathrm{G}_{\mathrm{yz}}$ \\
\hline 12000 & 8000 & 12000 & 0.2 & 0.2 & 0.2 & 3200 & 3200 & 3200 \\
\hline
\end{tabular}

Table 4. Inelastic parameters in tension regime

\begin{tabular}{|c|c|c|c|c|}
\hline$f_{t x}(\mathrm{MPa})$ & $f_{t y}(\mathrm{MPa})$ & $G_{f x}$ & $G_{f y}$ & $\alpha$ \\
\hline 1.5 & 0.25 & 0.08 & 0.007 & 1.35 \\
\hline
\end{tabular}

Table 5. Inelastic parameters in compression regime

\begin{tabular}{|c|c|c|c|c|c|c|}
\hline$f_{c x}(\mathrm{MPa})$ & $f_{c y}(\mathrm{MPa})$ & $G_{f c x}$ & $G_{f c y}$ & $\beta$ & $\gamma$ & $k_{c}$ \\
\hline 4.0 & 8.0 & 5.0 & 10.0 & -1.0 & 10.0 & 0.0005 \\
\hline
\end{tabular}




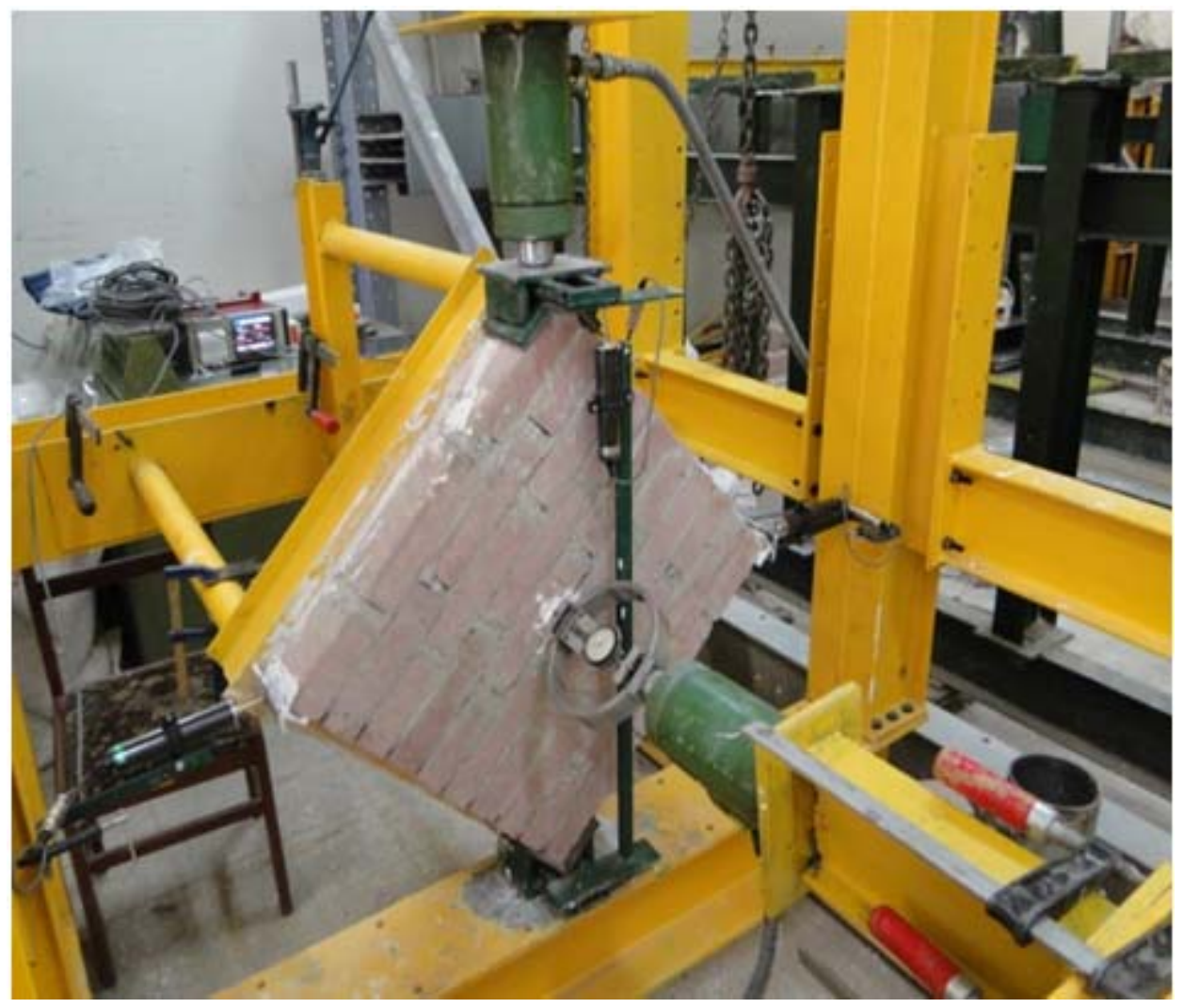

Fig. 1. Test set-up for simultaneous application of in-plane and out-of-plane loads
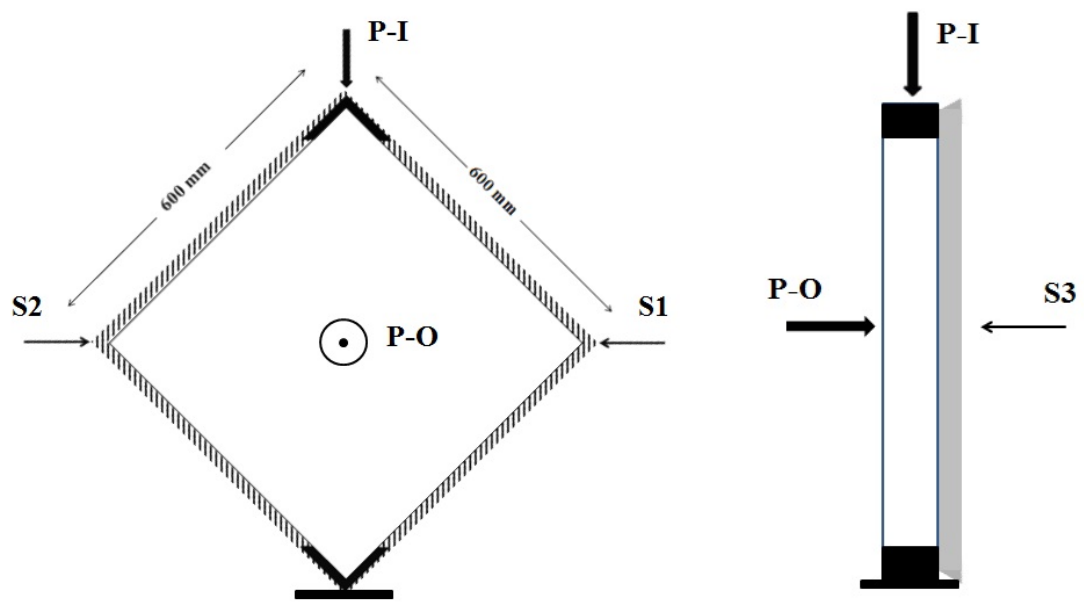

Fig. 2. Position of loading jacks (P) and LVDT sensors (S) 


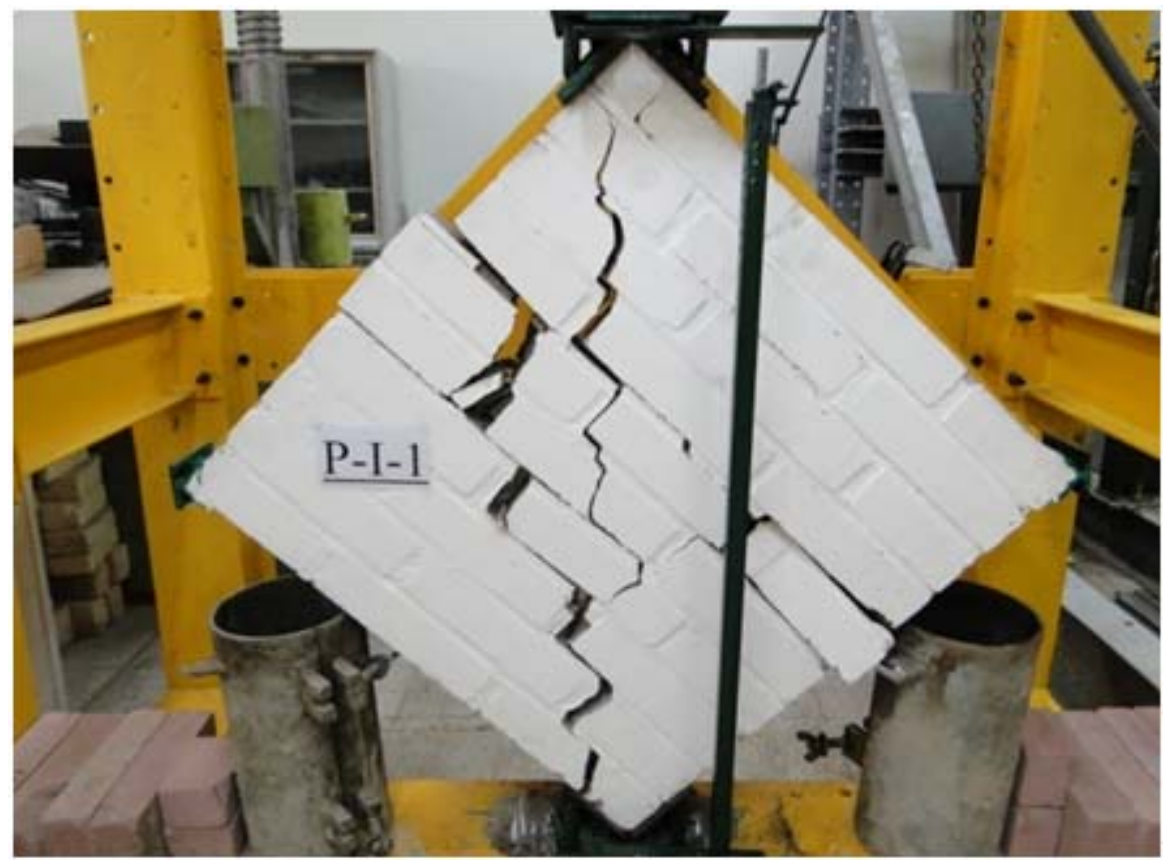

Fig. 3. Failure of the wall panels under in-plane shear load

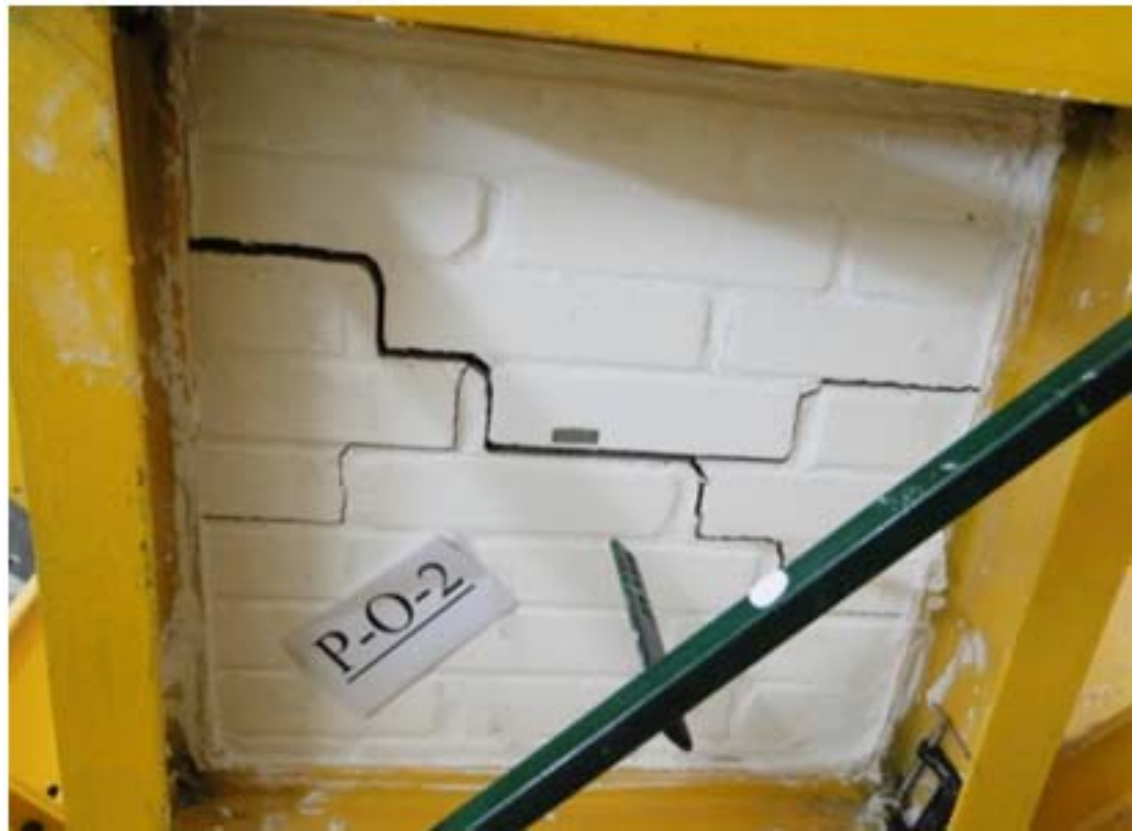

Fig. 4. Typical failure under two-way, out-of-plane bending of wall panels 


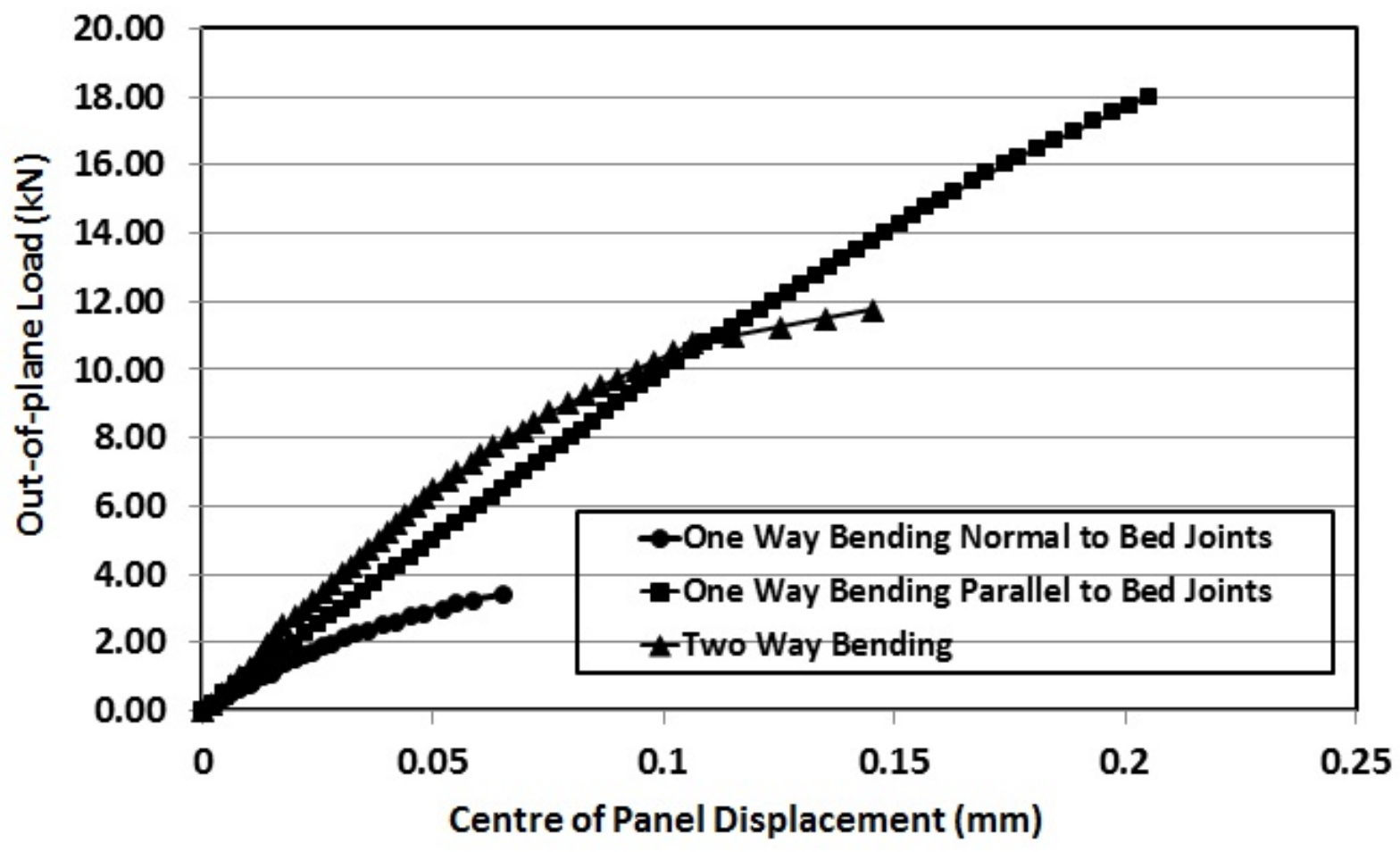

Fig.5. Out-of-plane load-displacement curves for different bending conditions (average response of three tests)

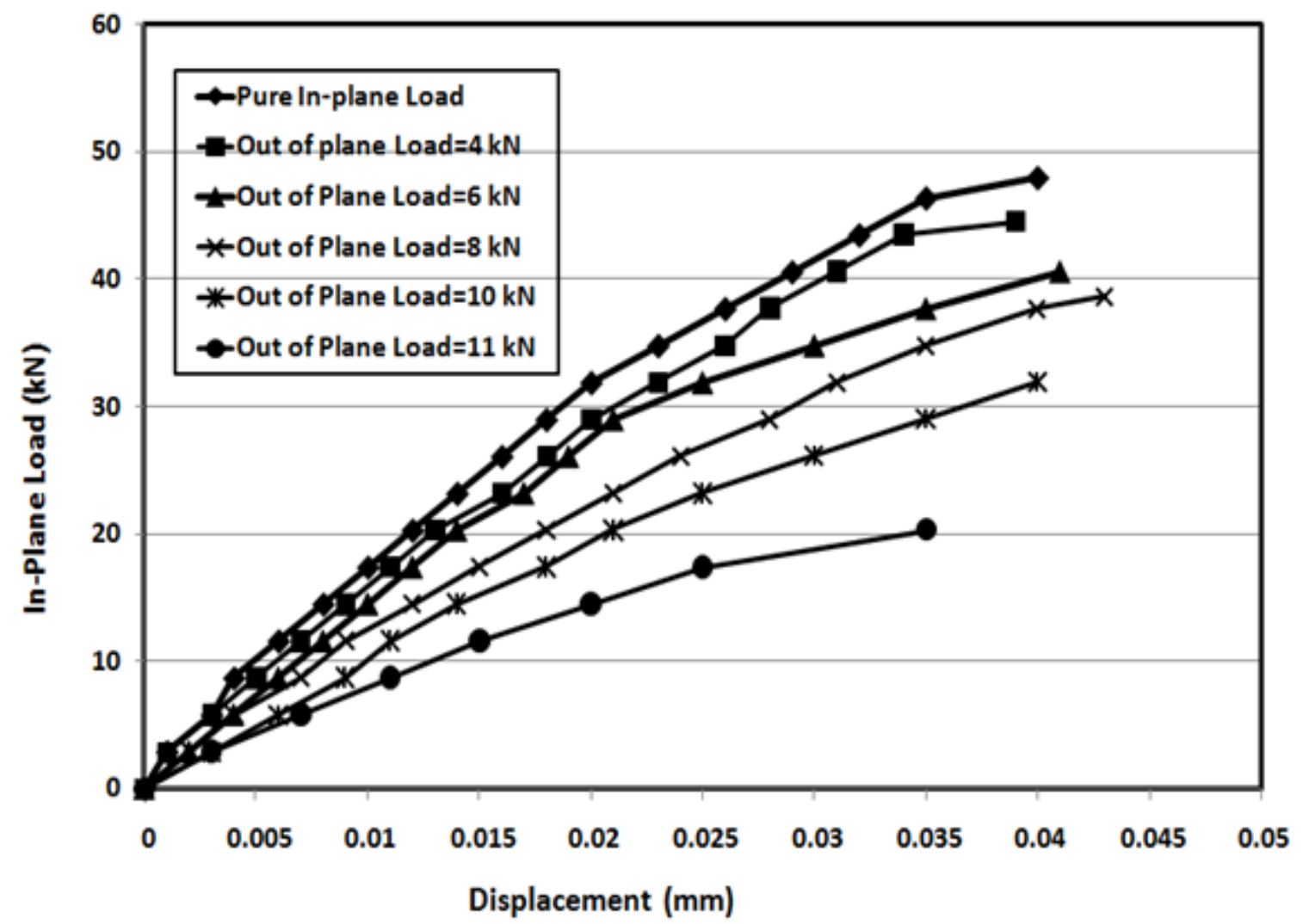

Fig. 6. In-plane load-displacement curves for different in-plane / out-of-plane load combinations (average response of three tests) 


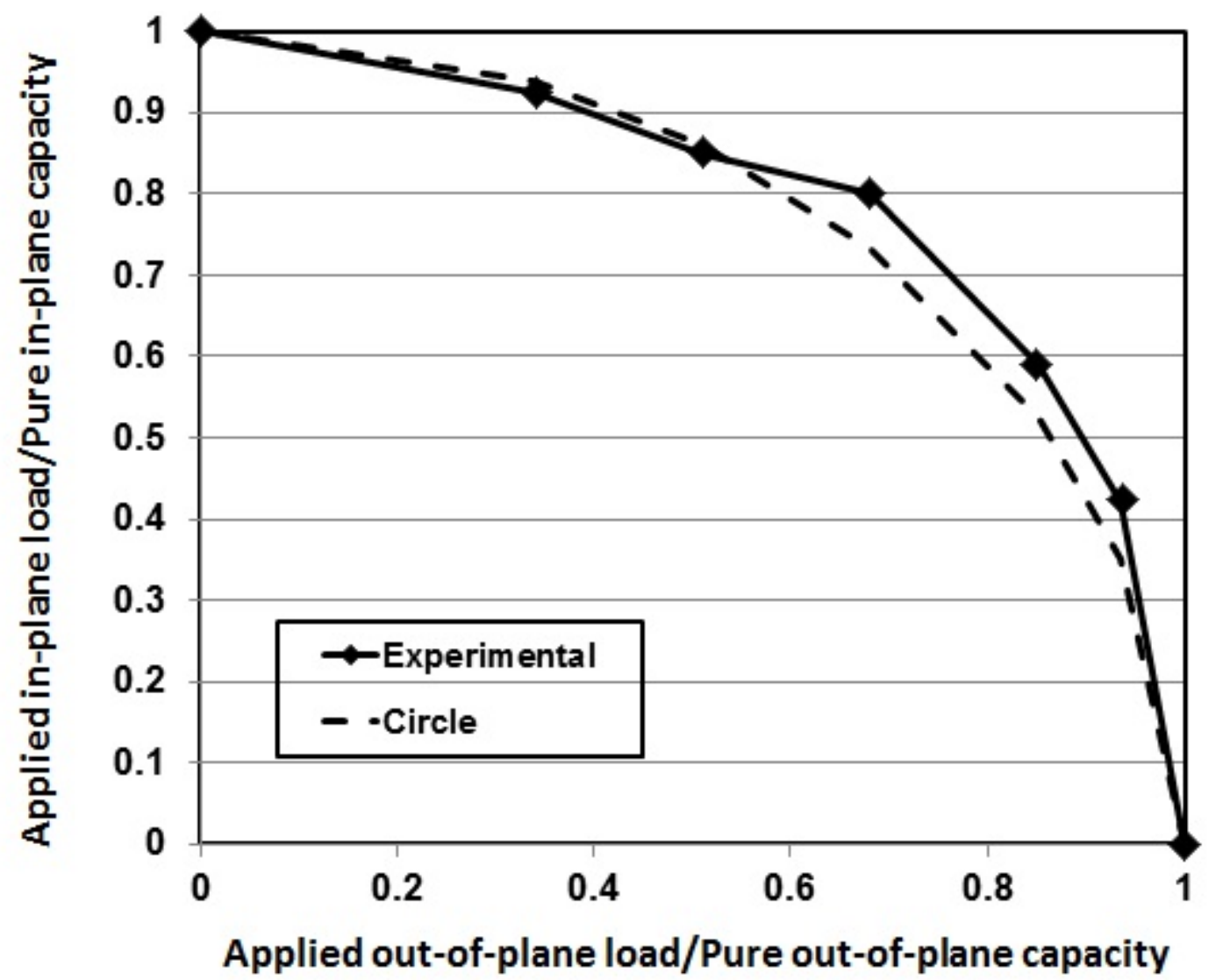

Fig.7. Normalized in-plane / out-of-plane capacity interaction curve for the wall panels

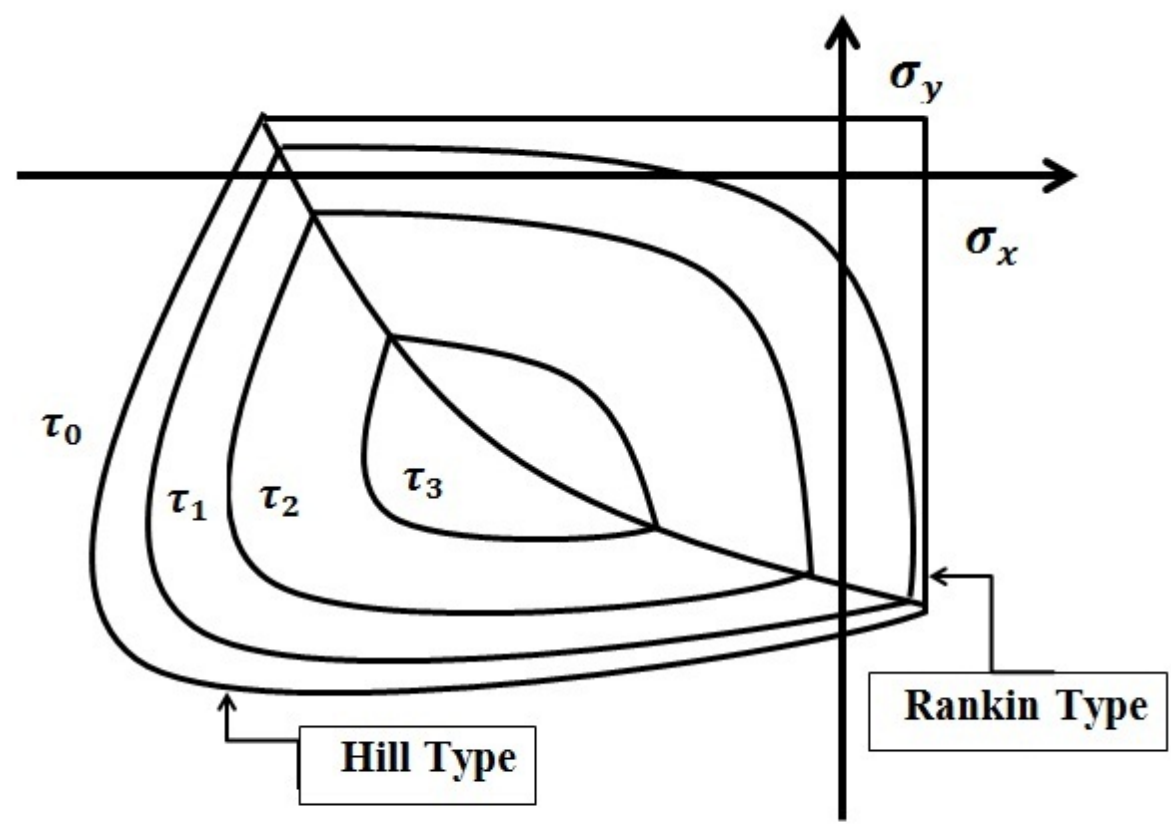

Fig. 8. The adopted plane stress anisotropic yield criterion [28] 


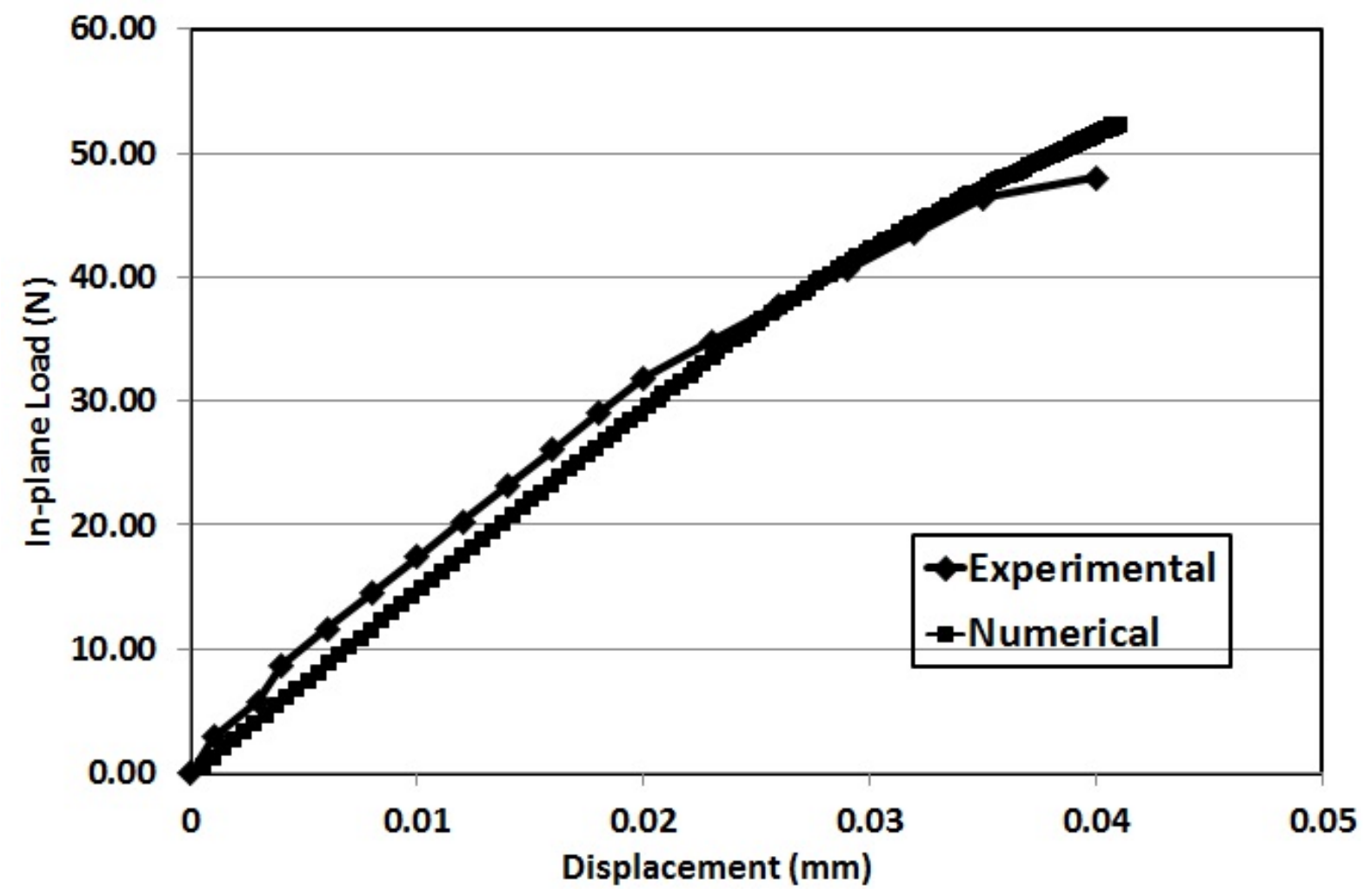

Fig. 9. Load-displacement curves for panel under in-plane loading

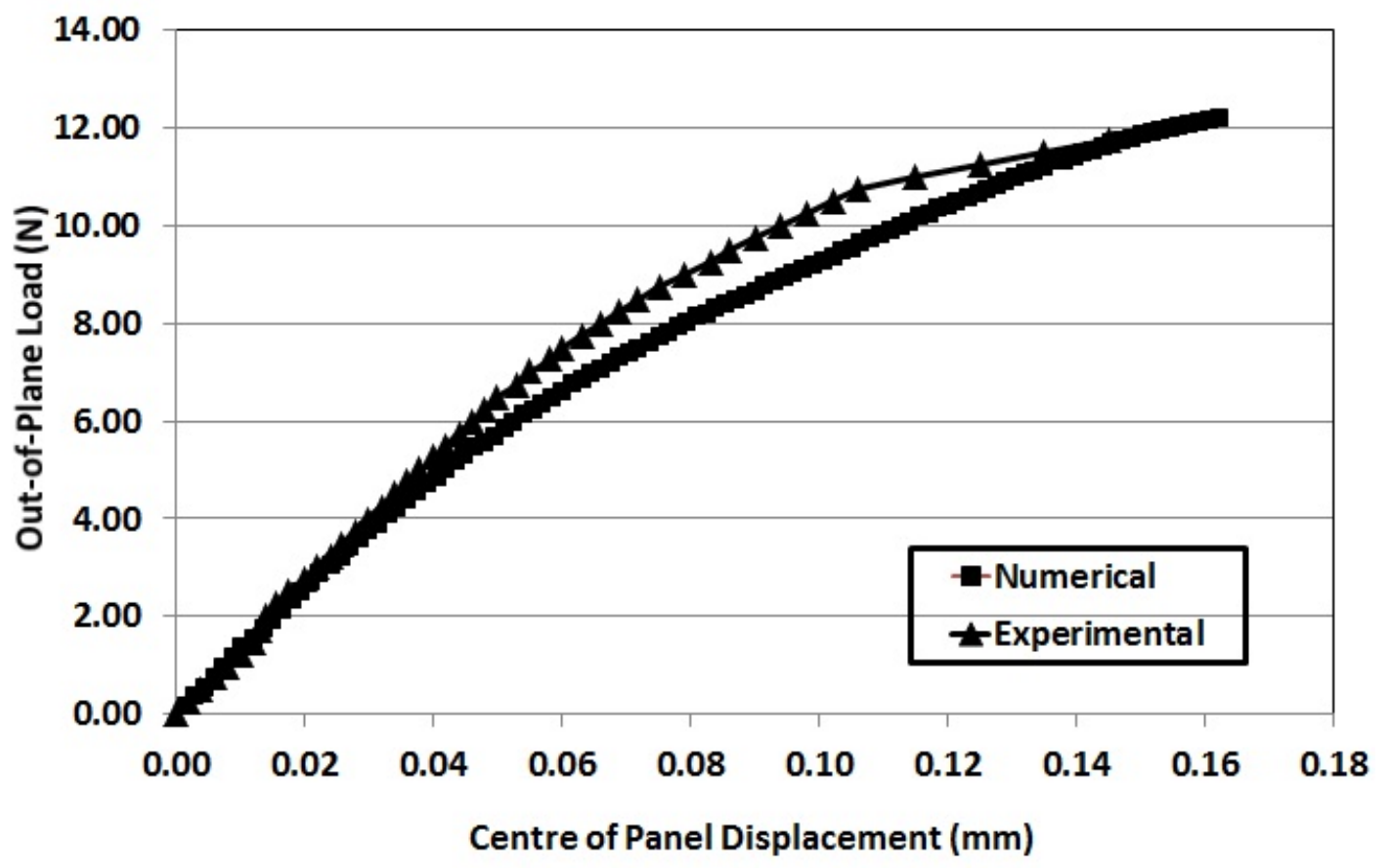

Fig. 10. Load-displacement curves for panel under out-of-plane loading 


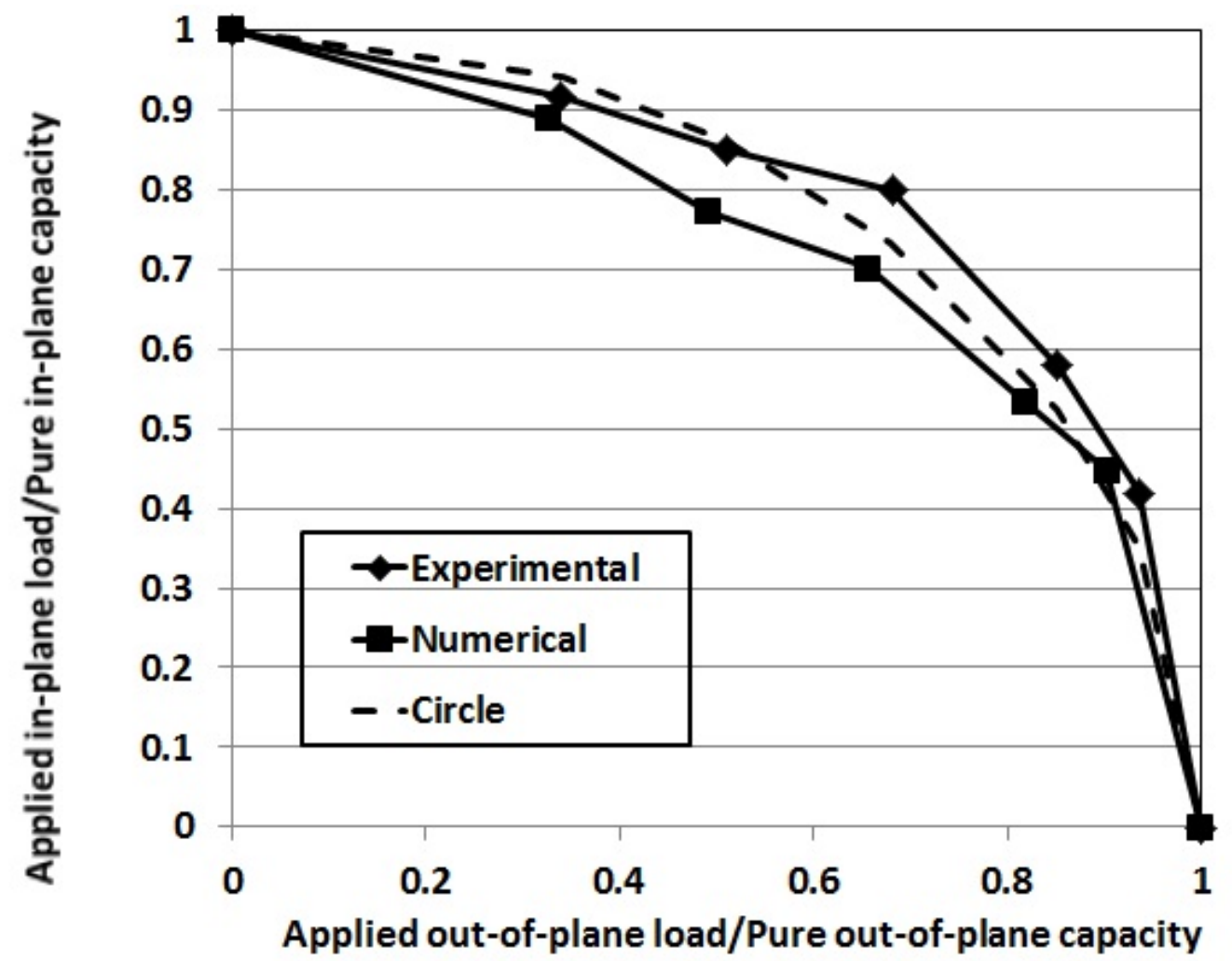

Fig. 11. Normalized in-plane, out-of-plane capacity interaction curves for the brick panel (a) (b)
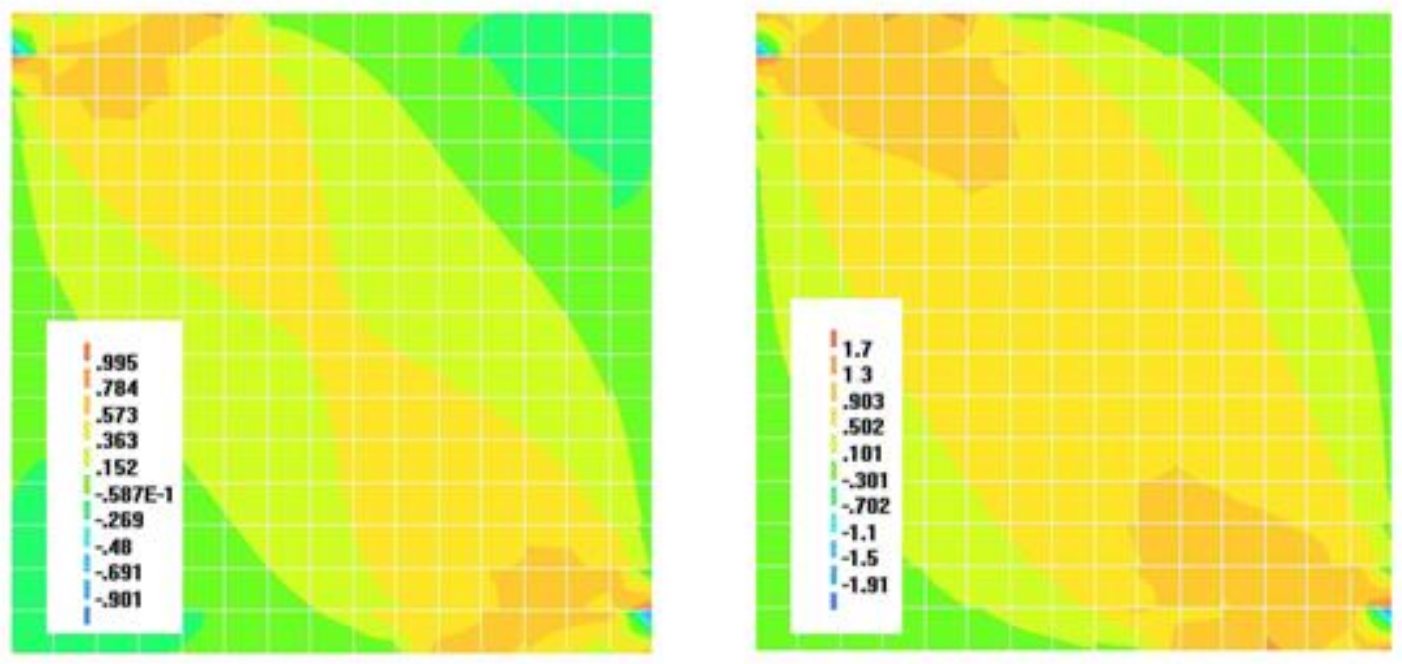

Fig. 12. Shear stress distribution in the brickwork of the square wall at the middle plane, 
corresponding to an out-of-plane load/capacity ratio of 0.4 at (a) $50 \%$ of the ultimate capacity and (b) at failure

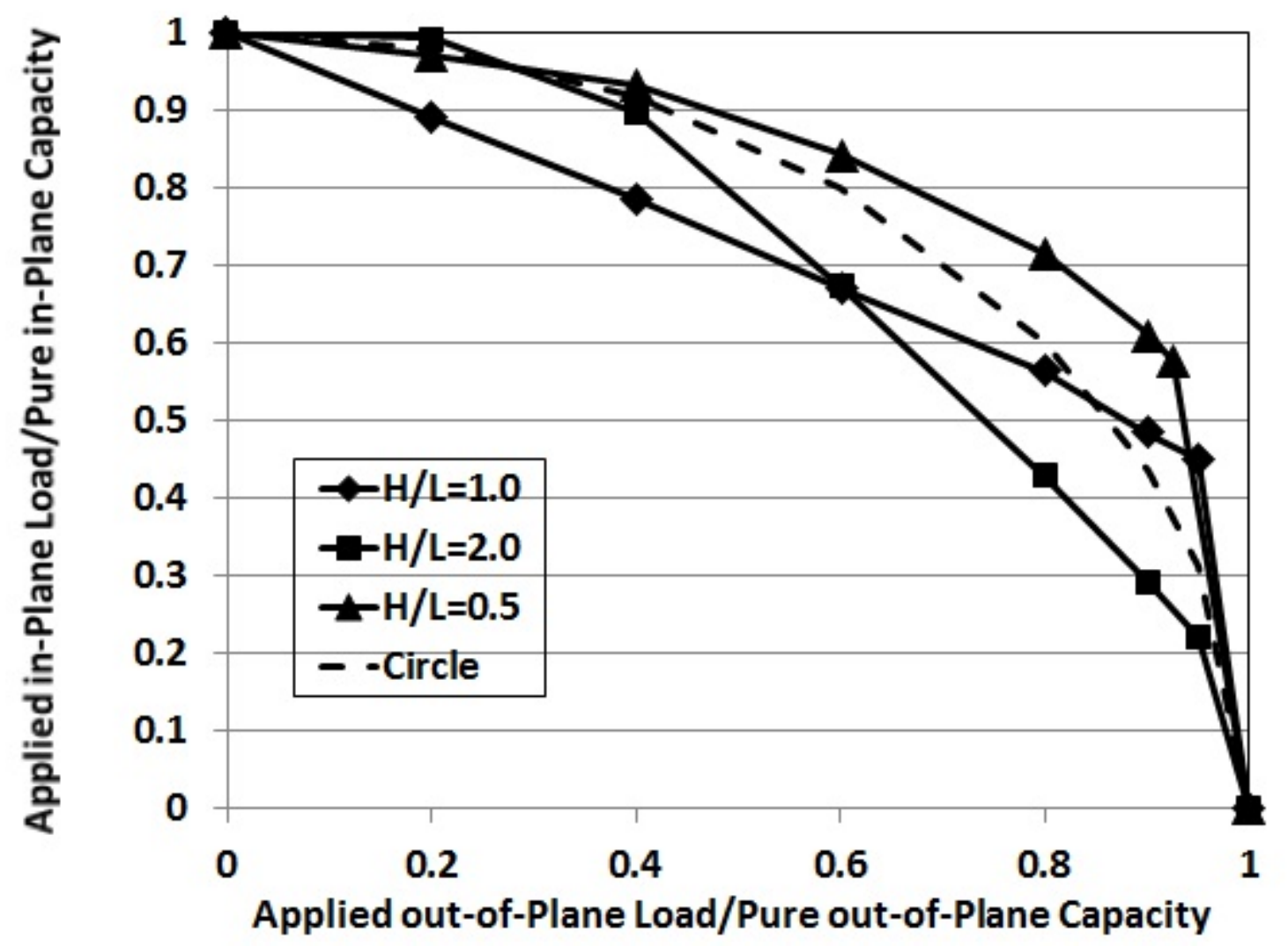

Fig. 13. Normalized in-plane, out-of-plane capacity interaction curves for the full-scale walls 